\title{
Burnout syndrome prevalence in physiotherapists
}

\author{
Blanca González-Sánchez ${ }^{1 *}$, María Victoria González López-Arza ${ }^{1}$, Jesús Montanero-Fernández ${ }^{2}$, Enrique Varela-Donoso ${ }^{3}$, \\ Juan Rodríguez-Mansilla ${ }^{1}$, José Carlos Mingote-AdáN ${ }^{4}$ \\ ${ }^{1}$ Medical-Surgical Department, Facultad de Medicina de la Universidad de Extremadura, Badajoz, Spain \\ ${ }^{2}$ Mathematics Department, Facultad de Medicina de la Universidad de Extremadura, Badajoz, Spain \\ 3Physical and Rehabilitation Medicine Department, Facultad de Medicina, Universidad Complutense de Madrid, Madrid, Spain \\ ${ }^{4}$ Coordinator, Comprehensive care program for ill healthcare professionals (PAISE), Madrid, Spain
}

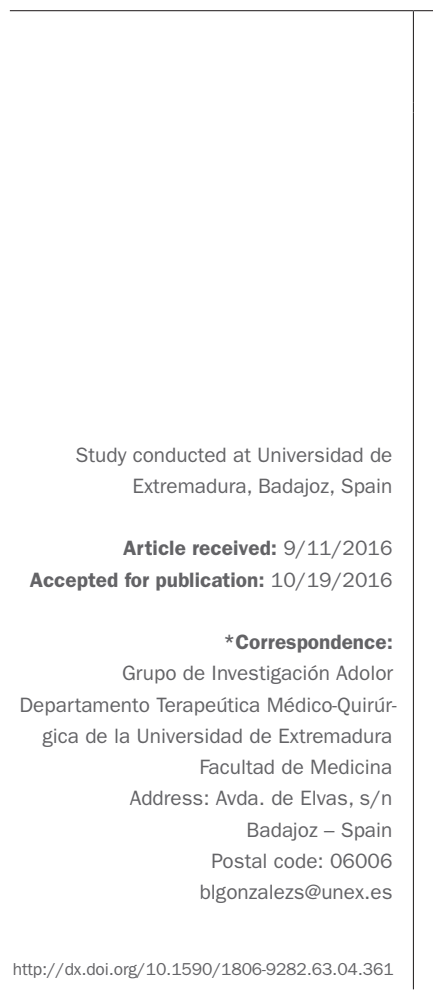

\section{SUMMARY}

Objective: To evaluate burnout syndrome in its three aspects, jointly as well as independently, in physiotherapists from the Extremadura region (Spain).

Method: Analytic descriptive epidemiological transversal trial in primary care and institutional practice, with physiotherapists practicing in Extremadura who met the inclusion criteria, after having signed an informed consent form. Emotional exhaustion, depersonalization and low professional accomplishment were the outcomes measured.

Results: Physiotherapists from Extremadura show a 65.23 point level of burnout syndrome, according to the Maslach Burnout Inventory questionnaire. Therefore, they are positioned in the middle of the rating scale for the syndrome, and very near to the high level at starting score of 66 points.

Conclusion: Physiotherapists in Extremadura present moderate scores for the three dimensions of burnout syndrome, namely, emotional exhaustion, depersonalization and low professional accomplishment. For this reason, they are in the moderate level of the syndrome and very near to the high level, which starts at a score of 66 points. No relation between burnout syndrome and age has been found in our study.

Keywords: burnout, physiotherapy, physical therapy.

\section{INTRODUCTION}

Healthcare personnel represents one of the working groups among which the majority of burnout syndrome (BOS) studies have been carried out. Along with educators, this group is probably the most affected by BOS. ${ }^{1}$ The majority of health professionals get involved for many hours with problems and worries of the patients they treat. Changes in the health sector generate increased competitiveness, leading to difficult situations that health professionals have to adapt to continuously. All of the situations above can disrupt the physical and psychological integrity of these professionals. ${ }^{2}$

Different studies demonstrate the occurrence of BOS in several professions. Many of these studies are focused in the health sector. However, few of them show its prevalence among physiotherapists, despite this being one of the most vulnerable groups. Wolfe $\mathrm{f}^{3}$ was the first to study BOS in physiotherapists, and he concluded that these professionals weren't exempt from suffering from this pathology.
The interest of this project is assessing the prevalence of BOS among physiotherapists who work in the Extremadura region (Spain). Physiotherapists who work in The Regional Health Service (public health), as well as those who work in the private sector were included.

The aim of our study was to assess BOS in its three dimensions: emotional exhaustion (EE), depersonalization (Dp) and low professional accomplishment (LPA) in physiotherapists working in Extremadura, as a group and independently. This will make it possible for us to know the syndrome's prevalence as well as its relations to sociodemographic and working variables, and the groups of affected physiotherapists.

\section{Method}

\section{Participants}

We have designed a descriptive and analytic transversal epidemiologic study. It has been carried out in the Auto- 
nomic Community of Extremadura. Participants were physiotherapists working in the region.

Inclusion criteria were: to be in active employment since the January 1, 2010 and to have been working at least one year, in a public or private practice. Exclusion criteria were: to be in sick leave at the moment of data collection or to not meet the inclusion criteria.

\section{Procedures}

To take part in the study, each participant was sent an envelope by regular mail, including: two questionnaires, one being the Maslach Burnout Inventory ${ }^{4}(\mathrm{MBI})$ and the other a sociodemographic and working variables questionnaire (SDLVQ); an informed consent with a cover letter; and the instructions. A pre-paid postage envelope was also sent for document return.

\section{Instruments}

SDLVQ: It consists of a general-purpose questionnaire specifically made for the study performance. It collects sociodemographic and working characteristics of the subjects. MBI: ${ }^{4}$ It is a questionnaire where the subjected is asked a series of questions on feelings and thoughts related to his or her work interactions. It consists of 22 items that are assessed by a Likert-type scale. The subjects are assessed through a range of six adverbs of frequency, from "never" to "daily" for each of the described by the items.

The three subscales of the $\mathrm{MBI}^{4}$ are constituted by three factors: EE, Dp and LPA at work.

Since our study assesses BOS in physiotherapists, the scale used will be the MBI-HSS, addressed to healthcare professionals, which is considered the classical version of the MBI, ${ }^{4}$ because it was the first to be elaborated. This scale consists of three subscales that measure the frequency in which professionals perceive EE. The professional feels he cannot give more of himself during his working time, in the emotional dimension or in the affective one. Moreover, they experience feelings of loss of hope, defencelessness, physical and psychological weakness, $\mathrm{Dp}$, as well as a negative attitude towards patients, a dehumanized vision of the patient, a feeling of LPA, negative self-evaluation in respect to his work performance, a feeling that the work is not worth the trouble and since nothing can be changed at work it is not worth trying anything new. This dimension, LPA, constituted as a reversed way to the other two dimensions (EE and Dp), has been criticized by some authors, because it can be a cause of disagreement among studies. Recently, working with items that assess inefficiency at work has been proposed as an alternative to reverse the non-efficacy items of the MBI.
Moreover, some studies ${ }^{5}$ have defended that while EE and Dp are clearly interrelated, LPA seems to be an independent and parallel variable, more related with the context "selfefficacy," which is a modulator of BOS. However, in our study we have used the dimension LPA.

BOS is classified in its three dimensions as: low, moderate and high level, according to the score achieved in each subscale.

\section{Statistical analysis}

Data was analyzed using SPSS 19.0 software. A value of $\mathrm{p}<0.05$ was adopted for statistical significance. One hundred and fifteen (115) professionals were studied in all. Significant correlation between joint numeric response (EE, Dp, LPA and total MBI) and the 18 categorical variables were searched by carrying out MANOVA test. The categorical variables that did not provide significant result in MANOVA weren't considered in the rest of the study. For the remaining categorical variables and for every component of MBI, ANOVA with Bonferroni method and Student's t-test were applied in order to understand the meaning of those correlations. Correlations between categorical variables as well as correlations between the components of MBI were also considered.

\section{Results}

The sample included 584 physiotherapists at first, and $22.43 \%$ of them replied a total of 131 questionnaires. After having applied inclusion and exclusion criteria, the sample remained in 116 subjects.

After carrying out the MANOVA test for every categorical variable, the only ones that provided significant results (we understand this as proof of correlation between these categorical variables and MBI) were: number of working days per week, type of working day, number of hours of direct attention to patients and family, number of patients and type of practice. The results are summarized in Table 1. We emphasized averages that turned out to be significantly higher according to ANOVA or Student's t-test.

LPA is clearly higher in the case of split shift working day as well as in private practice. Nevertheless, it can be understood as a redundancy since both categories are strongly associated, as we can see in Figure 1.

We can also note that more than 40 hours of direct attention is linked to higher scores in EE, and that more than 20 patients treated per day is associated with higher scores both in EE and Dp. Curiously, none of these five categorical variables, but number of working hours per week, which is also correlated with type of practice (Figure 2), provided any significant result for joint MBI. This fact can 
TABLE 1 Components of burnout syndrome for the main categorical variables; mean ( \pm standard deviation).

\begin{tabular}{lllllll}
\hline \multirow{2}{*}{ Total } & & N & EE & Dp & LPA & MBI \\
\hline Number of working hours per week & & 115 & $20.02(11.33)$ & $7.45(5.42)$ & $37.77(7.39)$ & $65.23(14.37)$ \\
\cline { 2 - 7 } & $>38.5$ & 52 & $18.08(10.62)$ & $7.42(5.5)$ & $36.46(7.86)$ & $61.96(14.26)$ \\
\hline \multirow{2}{*}{ Type of working day } & Consecutive & 43 & $19.23(10.69)$ & $8.09(8.81)$ & $35.19(7.97)$ & $62.51(14.21)$ \\
\cline { 2 - 7 } & Split shifts & 73 & $20.48(11.74)$ & $7.07(5.19)$ & $39.29(6.63)$ & $66.84(14.31)$ \\
\hline Number of hours of direct & $<10$ & 8 & $12.63(8.65)$ & $4.50(3.66)$ & $43.63(5.53)$ & $60.75(11.76)$ \\
\cline { 2 - 7 } attention to patients and family & $11-20$ & 12 & $14.50(10.81)$ & $4.75(3.86)$ & $40.08(8.24)$ & $59.33(13.42)$ \\
\cline { 2 - 7 } & $21-40$ & 65 & $20.05(10.39)$ & $7.68(5.38)$ & $36.72(7.19)$ & $64.45(14.04)$ \\
\cline { 2 - 7 } & $>40$ & 22 & $25.05(13.08)$ & $8.09(6.17)$ & $39.73(7.18)$ & $72.86(14.36)$ \\
\hline Number of patients treated per day & $<20$ & 55 & $16.93(10.23)$ & $6.36(4.86)$ & $38.84(7.15)$ & $62.13(13.49)$ \\
\cline { 2 - 7 } & $>20$ & 54 & $22.46(11.39)$ & $8.87(5.79)$ & $37.00(7.79)$ & $68.33(14.72)$ \\
\hline Type of practice & Public & 24 & $19.17(9.57)$ & $8.12(5.31)$ & $34.42(6.98)$ & $61.71(12.44)$ \\
\cline { 2 - 7 } & Private & 78 & $19.68(11.54)$ & $6.85(5.21)$ & $39.27(6.70)$ & $65.79(14.87)$ \\
\cline { 2 - 7 } & Both & 13 & $24.31(13.09)$ & $10.15(6.44)$ & $35.46(9.78)$ & $69.92(13.35)$ \\
\hline
\end{tabular}

EE: emotional exhaustion; Dp: depersonalization; LPA: low professional accomplishment; MBI: Maslach Burnout Inventory.

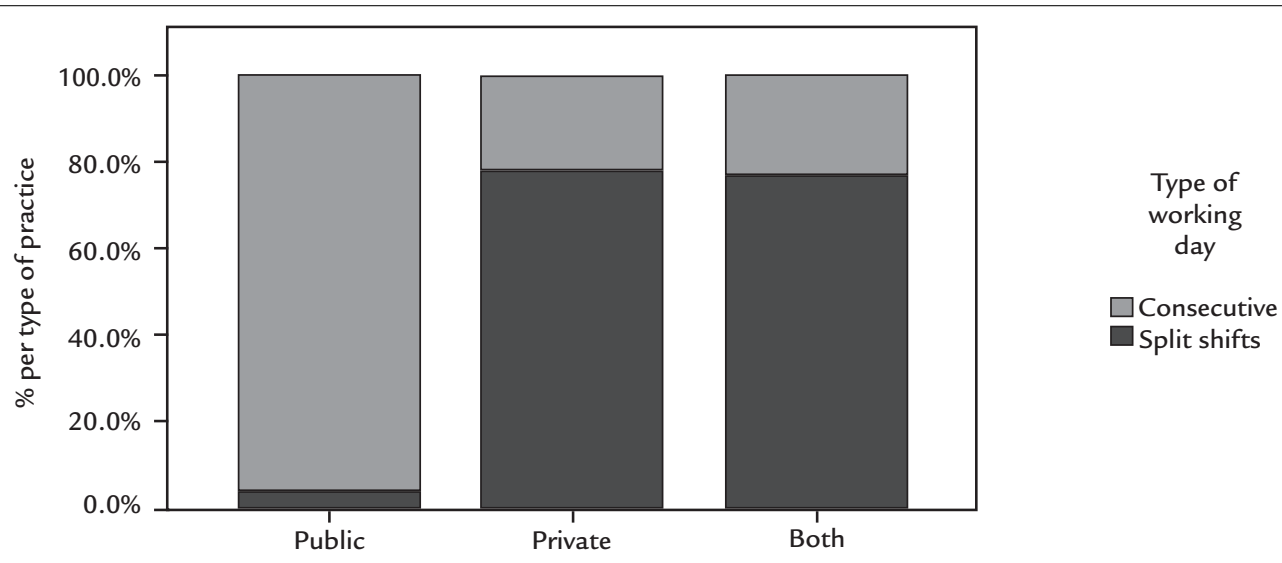

Type of practice

FIGURE 1 Type of working day per type of practice.

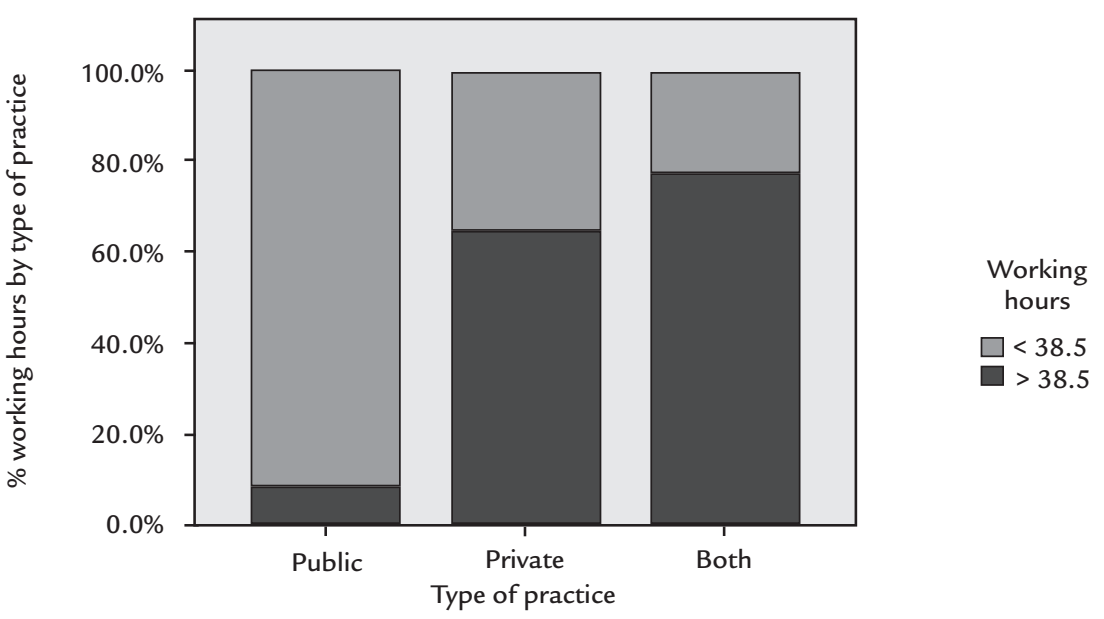

FIGURE 2 Working hours per week by type of practice. 
be statistically explained by LPA, providing significant inverse correlation with EE and $\mathrm{DP}(\mathrm{r}=-0.27$ and $\mathrm{r}=-0.33$, respectively), so that the different scores in Burnout I compensated most of the other variables.

\section{Discussion}

Some of the issues that have had an important influence in the results of our research are:

- Physiotherapist collaboration in our study was very low. Perhaps the low level of collaboration could be due to the questionnaires being sent by mail instead of an interview. The reviewed literature reflects lower rates of reply when the questionnaires are sent by mail. However, we thought that sending questionnaires through mail would be the best procedure in order to respect anonymous participation, as well as to reach to the higher possible number of professionals. This is because the Extremadura region comprises a very large territory.

- We avoided all bias selection risk. Questionnaires were sent to all physiotherapists from Extremadura and therefore they were all included in the study. No previous selection of professionals was done.

- In addition, a third party carried out the statistical analysis to avoid information bias.

- We must mention that in the reviewed literature, trials about BOS are very frequent. There are several trials focusing on healthcare personal, but very few focus on physiotherapists, therefore making data comparison with existing studies difficult.

Physiotherapists included in our study had a moderate level of BOS in its three dimensions: EE, DP and LPA. This tendency is in accordance with our literature references. Comparing our results with those of similar studies, we can see that in a trial done with physiotherapists in the Murcia region ${ }^{6}$ only $4 \%$ of participants showed high level of BOS, which is in correlation with other similar foreign studies. ${ }^{7}$ In a study made in Mexico ${ }^{8}$ about BOS in physicians and nurses, $36 \%$ of the sample showed moderate-high levels of BOS. If we compare our results with those obtained from other health professionals, we can see that physiotherapists show BOS levels similar to physicians and nurses. In a study ${ }^{9}$ performed in the Madrid region, BOS levels and their three dimensions showed a moderate level in $50 \%$ of the participating nurses.

Regarding controlled variables and BOS components, we have observed no significant relation between BOS and the participants' age, which is in accordance with the reviewed literature. So, the age of physiotherapists does not seem to have any influence in the syndrome. However, there is an adjustment period, at the beginning of the physiotherapist's professional development, where they are especially vulnerable to the development of BOS.

Marital status influences the final stages of BOS, as well as the levels of its three dimensions. With the data shown above, we reaffirm the theory that BOS is associated with people who do not have a stable partner and, although there is no consensus, it seems that the familiar environment cushions the effects of work stress and compensates emotional over implication in work, as affirmed by Dale and Weinberg. ${ }^{10}$

After having analyzed the bibliography, we can see that neither the number of working hours per week nor the type of shifts in a working day can negatively affect the levels of BOS and its three dimensions. In a study carried out by Bernaldo de Quirós and Francisco and Labrador, ${ }^{11}$ the authors show a strong correlation between work time (spent in the exercise of profession) and BOS. The study of Serrano Gisbert et al. ${ }^{6}$ shows that almost $75 \%$ of physiotherapists who suffer from BOS work more than seven hours per day. The study by Gran, Suñer and García ${ }^{12}$ shows highest levels of $\mathrm{Dp}$ in professionals who work night shifts. Data presented in our study affirm these theories, because physiotherapists who work split shifts and more than 38.5 hours per week are those who present the highest levels of BOS. In relation to the three dimensions, for working day, moderate levels are present in both groups, except for $\mathrm{Dp}$, a disturbance that is highest in those professionals who work less than 38.5 hours per week; however, they are in the moderate level range. LPA is low in physiotherapists who work split shifts. The number of hours of direct attention to patients and family represents a factor that influences negatively the levels of BOS and its three dimensions, because professionals who dedicate more than 40 hours per week to this issue are those who present the highest level of $\mathrm{EE}$ and $\mathrm{Dp}$. Both parameters show moderate levels. LPA is lower in professionals who dedicate less than 10 hours per week to direct attention to patients and family, representing moderate levels. Burnout syndrome reaches its highest levels in those who dedicate more than 40 hours per week of direct attention to patients or family. We can establish that this group is highly affected by BOS. A study carried out in a sample of physiotherapists from a health service in Andalucía ${ }^{13}$ did not find any significant statistical relation between $\mathrm{BOS}$ and the number of hours dedicated to direct patient attention.

With respect to the number of patients attended to daily and BOS, our results are very similar to those mentioned in the previous paragraph. Professionals who attend 
to more than 20 patients per day have the highest levels of EE, Dp and BOS. Both EE and Dp dimensions present moderate levels and BOS presents high levels. LPA is lower in those who attend to less than 20 patients per day, showing moderate levels. This is in accordance with reviewed authors such as Atance Martínez ${ }^{14}$ and another study carried out in The Madrid Regional Rehabilitation Service. ${ }^{15}$ In the latter, BOS is associated to excess of work. These results differ from those obtained by Castro Sánchez et al. ${ }^{13}$ in a sample of 46 physiotherapists from a health service in the Andalucía region where a significant relation between $\mathrm{BOS}$ and the number of daily treated patients was noted.

Finally, in our study, EE is high in physiotherapists who work in private practice. $\mathrm{Dp}$ is moderate in those who have both, private and public practice. LPA is low in those who work in private practice. Burnout syndrome levels are high in those who work both (private and public). There are very few studies in this field. If we compare our results with those obtained by other authors, such as Schuster et al. ${ }^{7}$ or Serrano Gisbert et al., ${ }^{6}$ our results would not be in accordance with them. The relation between the number of working hours per week and the kind of work day shows that more than half of the physiotherapists who work split shifts work more than 38.5 hours per week. Conversely, most of those who work on consecutive days carry out less than 38.5 hours per week.

We have not found any studies regarding work day in respect to public or private practice performance. However, with our results, we can affirm that more than half of the physiotherapists who have participated in the study work in private practice and, since physiotherapy is a healthcare profession, it is in the private sector that assistance time is higher and better adapted to the type of patients.

Both who work more than 38.5 hours a week and who work less than 38.5 hours a week do not present differences in the number of hours of direct care to patients or their relatives. In both groups, more than half of the participants dedicate between 21 to 40 hours per week to it. Regarding these data, we can establish that more than 50\% of a physiotherapist's working day is dedicated to direct attention, thus taking time that could be dedicated to other important activities such as study, research and training. These results are in accordance with the research done by Schuster et al.,7 who affirm that factors such as excess of activity represent negative prediction variables towards work, thus making health professionals very frequently a risk group for this kind of disturbance development.
We must point out that more than half of the physiotherapists who work in private practice do it for over 38.5 hours per week; and more than half of those who work in public practice do it for less than 38.5 hours per week. This is so because, in Spain, the public sector's working week never exceeds 35 hours.

\section{Conclusion}

Physiotherapists from the Extremadura region have a BOS level of 65.23 points, according to the MBI questionnaire.

A high burden of care, whether considering the number of patients or the number of hours of direct care), raises the scores of EE and Dp. The total number of hours is reflected in the total. Typically, in the private sector, starting day is associated with a high score in LPA.

No relation between BOS and age has been found in our study.

\section{Conflict of interest}

The authors declare no conflict of interest.

\section{References}

1. Arís Redo N. El síndrome de Burnout en los docentes de educación infantil y primaria en la zona del Valles Occidental [thesis]. Barcelona: Universidad Internacional de Cataluña. Departamento de Ciencias de la educación; 2005.

2. Maslach C. Burnout: The cost of caring. New York: Prentice-Hall Press; 1982

3. Wolfe GA. Burnout of therapist: inevitable or preventable? Physical Ther. 1981; 61(7):1046-50.

4. Maslach C, Jackson S. Maslach Burnout Inventory. Palo Alto: Consulting Psychologist Press; 1981.

5. Gálvez M, Moreno B, Mingote-Adán JC. El desgaste profesional del médico. Más Dermatol. 2011; 15:16-9.

6. Serrano Gisbert MF. Estrés laboral en personal sanitario. Fisioterapia. 2002; 24(Suppl 1):33-42.

7. Schuster ND, Nelson DL, Quisling C. Burnout among physical therapists. Phys Ther. 1984; 64(3):299-303.

8. Ortega Herrera ME, Ortíz Viveros GR, Coronel Brizio PG. Burnout en médicos y enfermeros y su relación con el constructo de personalidad resistente. Psicología y Salud. 2007; 17(1):5-16.

9. Albaladejo R, Villanueva R, Ortega P, Astasio P, Calle ME, Domínguez V. Síndrome del Burnout en el personal de enfermería de un hospital de Madrid. Rev Esp Salud Pública. 2004; 78(4):505-16.

10. Dale J, Weinberg RS. The relationship between coaches' leadership style and Burnout. Sport Psychol. 1989; 3(1):1-13.

11. Bernaldo de Quirós M, Labrador FJ. Relaciones entre el estrés laboral, el Burnout y síntomas psicopatológicos en los servicios de urgencia extrahospitalaria del área 9 de Madrid. Ann Clin Health Psychol. 2008; 4:53-61.

12. Gran A, Suñer R, García M. Desgaste profesional en el personal sanitario y su relación con los factores personales y ambientales. Gac Sanit. 2005; 19(6):463-70.

13. Castro Sánchez A, Rodríguez Claro ML, Lorenzo CM, Vicente Martín C, Arroyo Morales M, Fernández ZF. Prevalencia del síndrome de Burnout en Fisioterapia. Fisioterapia. 2006; 28(1):17-22.

14. Atance Martínez JC. Aspectos epidemiológicos del síndrome de Burnout en personal sanitario. Rev Esp Salud Pública. 1997; 71(3):293-303.

15. Expósito JA, Echevarría C, Pino R, Díaz P, Algarín MI, Cayuela A. Prevalencia y factores asociados al síndrome de estar quemado (Burnout) en los servicios de rehabilitación. Rehabilitación. 2004; 38(2):59-65. 